\title{
TOWARDS A MORE EFFECTIVE ENGAGEMENT OF LEARNERS AND TUTORS IN ONLINE DISCUSSION FORUMS
}

\author{
Zoraini Wati Abas (zoraini@oum.ed.my) \\ Mansor Fadzil (mansor@oum.edu.my) \\ Open University Malaysia
}

\begin{abstract}
Online discussion forums have the potential to add value to the total learning environmental in open distance learning. A study analyzing more than a hundred online forums from twenty offered by four faculties was conducted at the Open University Malaysia (OUM). The study aimed to determine how effective online forums were in contributing to the blended learning pedagogies adopted by the university. Using the Community of Inquiry model to evaluate the effectiveness of the forum discourse, the forums were examined to determine the extent of social presence, cognitive presence and teaching presence in the forums. The study also looked at similarities and differences in interactions in the various forums. Several interesting observation were made as a result of the analysis. One major observation made was the need for tutors to be trained on how to field questions, pose questions and lead as well as moderate the discussions. The study was timely to ensure that online discussion forums contribute further to the blended learning environment at OUM.
\end{abstract}

Keywords: blended learning, community of inquiry, online discussion.

The Open University Malaysia (OUM) seeks to be a university for all. It has been regarded as a fast growing institution in the region with students numbers growing from 753 to over 70,000 within seven years. It offers more than 50 diplomas, degree and graduate degree programmes to student within and outside Malaysia. OUM practices blended learning to educate its learners. Its blended approach consists of: self-managed learning through print modules and accompanying e-content; face-to-face interactions in classroom settings and online forum discussions through the university's myLMS, a learning management system.

Among others, myLMS provides a platform for online interactions between the tutor and learner as well as between the learners. From the time the institution first started, it has insisted that online learning be made a significant portion of the pedagogical blend for each and every course offered by OUM. The online learning component comprises e-content delivered through myLMS as well as discussions moderated by the tutors in the online forums. To encourage students to go into the forums, five percent of the course marks are awarded to them for frequent and quality contributions.

Typically, a 3 credit hours OUM course consists of 95 hours of self-managed learning (80\%), 10 hours (8\%) of face-to-face learning and 15 hours (12\%) of online learning. All learners at 
OUM are required to make their presence felt in the online discussion forums provided for every course they take. All tutors are expected to lead and moderate the forum to support the learning process. The important role tutors play is supported by a study by Abas and Kaur (2004) where it was found that students depended on their tutors to ensure their success with online learning, particularly through discussion forums. The study also found that after more than a year of implementation, most OUM tutors understood the process of online learning and their role in online learning. A large majority $(96.6 \%)$ of the tutors who responded to the study agreed that online learning is an important component of learning at OUM.

The primary aim of the online discussion forum at OUM is to further support the achievement of learning outcomes set for each course. More specifically, it should strengthen learning by ensuring that learners understand the key concepts presented in the print module. The forums were initially established to enable learners to seek their tutor's help when needed. Gradually, tutors were asked to support the development of knowledge-building communities among their learners based on constructivist learning principles. This meant that the forums should engage the learners in a series of discussions on various topics covered in the print modules. Learners were expected to contribute to the discussions by sharing their views, ideas, knowledge and opinions or relate their experiences in relation to the topics being discussed. This includes sharing of valuable information and useful resources that are on the Internet for the benefit of their course mates. The ultimate aim was to establish a valuable online learning community for learner. The tutors who support the development of online leaning communities are the same tutors of the learners they meet face-to-face.

After seven years in operation, the university decided that a study to determine how well tutors were supporting their learners online be carried out. Its objective was to see how far OUM has succeeded in providing the right environment for learning and to see how far OUM tutors have understood their roles.

\section{The Study}

The main objective of the study was to determine the interaction between tutors and learners and the interaction among learners in the online discussion forums. Each forum was analysed for the extent of its social, cognitive and teaching presence, respectively. The study focused on 137 forums from 20 subjects which had been offered for at least three or more semesters by four faculties (Faculty of Business Management, Faculty of Information Technology and Multimedia Communication, Faculty of Science and Technology and Faculty of Education and Languages). The study was regarded as a mission critical research. Prior to the conduct of the study, the research proposal was presented to and approved by the members of the Group Management Committee of OUM.

\section{THEORETICAL BACKGROUND}

\section{Online Discussion Forums}

According to Luppicini (2007), there has been a great deal of interest in distance education over the last decade. Online learning communities are a valuable add-on to instruction in online and blended learning environments. These communities developed through online 
discussion forums can support reflection and other forms of higher-order thinking which will enhance students' learning (Hannafin, Land, \& Oliver. 1999). As noted by Muilenburg and Berge (2000), the majority of distance courses rely heavily on online forums as they help play a vital role in establishing a learning community through which learners generate knowledge. $\mathrm{Li}$ (2004) observed that while online forums are important in both distance and blended learning environments to promote collaborative knowledge building, a clear guidance is needed to ensure that appropriate strategies are employed to meet the goals of the online forums.

Previous research at OUM has recommended various strategies for the implementation of online learning. This includes the proposal for a collaborative online learning by Kuldip and Abas (2004) where students will be doing the first part of their assignments by discussing online with their course mates. Here, learners can test their understanding and problemsolving skills through discussions and problem solving.

In 2004, it was proposed that for online learning to be more effective, students should be encouraged to discuss part of their assignments online as a group and include conclusions from the discussion in their individual assignments (Kuldip \& Abas, 2004). Although it was generally believed that most if not all tutors understood how to support online learning, there were no subsequent studies to determine the actual situation. On the other hand, fewer students were complaining about the lack of online support from tutors.

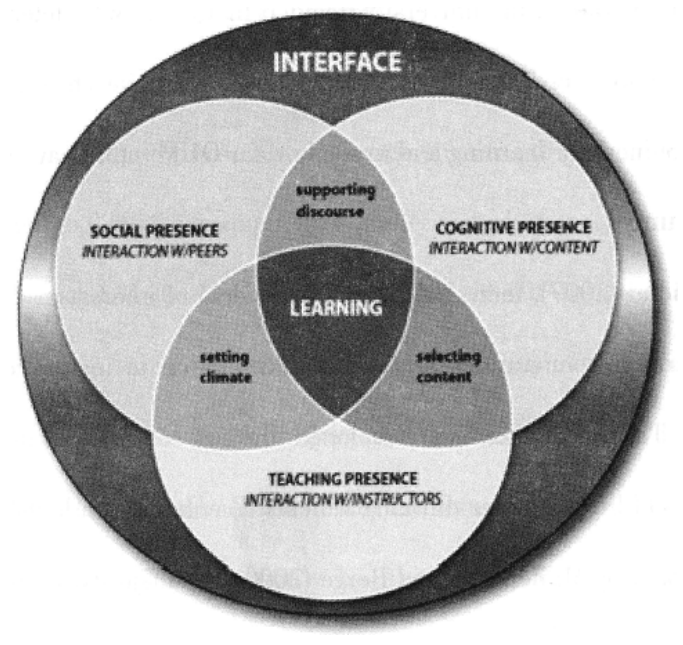

Figure 1. Community of Inquiry Model (Garrison, Anderson \& Archer, 2000)

Various models to ensure successful online learning have been proposed. The Community of Inquiry (COI) model by Garrison, Anderson and Archer (2000) and the cybergogy model (Wang \& Kang, 2006). The cybergogy model advocate the importance of three overlapping and intersecting domains (cognitive, emotive and social) to produce engaged learning. The more established COI model (see Figure 1) comprises three important elements: social, cognitive and teaching presence also overlapping and intersecting each other to produce learning. To model conceptualises that meaning is constructed and confirmed through 
sustained discourse in a critical community of inquiry (Garrison \& Archer, 2000). The COI model was selected for the study and was used to analyse the interactions in the forums selected for the study. It was also seen as a vehicle to help learner move from doing independent learning to group collaborative learning (see Figure 2) so as to benefit from real world experiences.

\section{The Community of Inquiry Model}

The goal of the $\mathrm{COI}$ model is to create a learning community based on an inquiry approach where students are fully engaged in collaboratively constructing meaningful and worthwhile knowledge. From both a theoretical and empirical perspective, it is necessary that the interaction and collaboration among learners be effective in order to achieve deep dan meaningful learning outcomes. As Garrison (2006) noted, the challenge in implementing the $\mathrm{COI}$ model is how to integrate all the presences (social, cognitive, and teaching) to contribute to a collaborative-constructive learning process. The integration of the presences is what will give rise to collaborative constructivist learning.

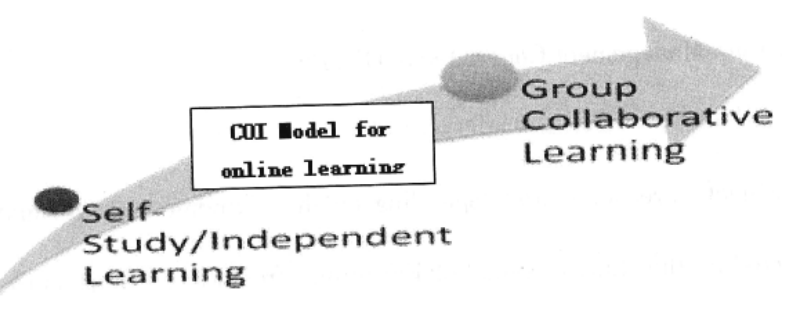

Figure 2. COI model as a means to mobilize learning from self-study/independent learning to group collaborative learning

In explaining what these presences refer to, Garrison, Arbaugh, Cleveland-Innes, Diaz, Ice, Richardson, Shea, \& Swan (2008) define social presence as the ability of participants to feel belonged to the community such as course of study. Participants should feel comfortable and are able to communicate purposefully in a trusting environment and at the same time, develop inter-personal relationships with access mates. Cognitive presence is the extent to which learners are able to construct and confirm meaning by being albe to reflect and engage in a discourse in a critical community of inquiry. Teaching presence refers to how tutors design, facilitate and direct the cognitive and social processes for the purpose of realizing personally meaningful and educationally worthwhile learning outcomes.

It is believed that the $\mathrm{COI}$ model has the potential to produce meaningful learning through group discussions where participants collaborate and help each other build up their understanding of the subject matter. Hence, the study applied the COI model to determine the extent of the social, cognitive and teaching presences. It would allow OUM to gauge the gap between what is currently happening with what should happen once the COI model is applied in the near future. 


\section{METHODS}

For each subject, three or more, depending on the abundance of "discussion" of the most active forums were selected for the study. A total of 137 forums from the 20 subjects identified were selected for analysis. Twenty teams were organised to help with the analyses, each team doing one subject. Each team comprised Subject Matter Experts (SMEs) who were either fulltime faculty members or part-time tutors. Coordinated by the lead researcher from the Center for Quality Management and Research \& Innovation (CQMRI), the SMEs and tutors were invited to a workshop conducted over a weekend. It was a focused effort with the main researcher leading the way on how to analyse the forum interactions. All selected forums were available in soft as well as hard copies.

The lead researcher described the steps employed for the analysis. An instrument was prepared to help participants capture the analysis and observations. Participants were asked to peruse the forums in a systematic way to look for the nature and characteristics of the interactions. They were to look for evidence of teaching presence, social presence and cognitive presence and report on their observations of the interactions by using the instrument provided to record the analysis or perception of interactions in the forums. Each team had another member of the group cross check for similarities or differences in observations. For each tutorial group analysed, members of each team discusses with the aim of reaching a final agreement that everyone will he happy with in terms of the analysis/perception of the interactions in the forums of that particular tutorial group.

Finally, each group prepared a summary of the analysis and gave recommendations for future implementation of online discussion forums for more effective learning at the university. The group next viewed the respective findings and discussed the recommendations for the future. The lead researcher next presented the analyses together with the recommendations to members of the academic board two weeks after the workshop.

\section{RESULTS AND DISCUSSION}

It was found that while tutors and students initially appeared to be interacting actively in the forums, when further examined for social, cognitive and teaching presence, the quality of interactions that would be necessary to create each of the presence was found to differ from tutor to tutor. While some tutors were effective, others were less so. Those who were observed to be effective had succeeded in creating a warm social environment where learners were also found to be more active in posting their messages. However, what messages were posted depended on how the tutors were able to lead and bring the learners on track. On the other hand, there were tutors who were rarely present online and failed to respond to some of the important postings by their students. Interestingly some of these forums had the students very actively posting to each other on a variety of topics in spite of the tutor's absence.

One out of the 137 forums examined was considered exceptional in terms of the social, teaching and cognitive presence. Through his postings, the tutor projected his passion for his role as a tutor, ensuring that students were on track with their assignments and understanding of the subject matter as well as that they felt belonged to the group. He appeared to have gone out of the way to reach out to students who appeared troubled, "lost" or was missing the 
forums. He tried to motivate, inspire and appeared to be warm and caring. He was also prompt and timely with his responses to student postings.

The team for this subject had recommended that if there were a Best Online Tutor award, it should be awarded to this particular tutor. He seemed to have modelled the right online behaviour. Other tutors can learn from the way he built a learning community based on the creation of the three types of presence.

Another observation but unique to quantitative subjects such as mathematics, was that interactions were more frequent at the beginning of the semester but trailed off towards the end of the semester. It was noted that in quantitative subjects, use of mathematical symbols were necessary. This was not catered for and was said to be a main contributor to a much lower level participation in the forums of quantitative subjects.

The study had also resulted in another form of achievement. It was found that most of the tutors who were involved in the study had also learnt from some of the interactions in the forums they examined. They discovered some good and poor examples. At the end of the workshop, they proposed several recommendations for further empowers learning through effective online discussions.

Based on the analyses of 137 forums from 20 subjects offered by four faculties, the study recommended of few suggestions for future tutors to do in order to ensure the creation of social, cognitive and teaching presence. This includes creating a warm and inviting environment which students will be drawn to; modelling appropriate online behaviour through the language used and style of communication to create a friendly, inspiring and motivating environment; establishing a caring and sharing environment where learners will learn from each other with tutor guidance. It is important that the warm and inviting environment is established from the start because as Dabbagh (2007) highlighted, a student's academic selfconcept is a key predictor for success in a distance education setting.

It was also recommended that tutors should help learners construct learning. Among others, the tutor should praise rather than criticise so as to provide a motivating environment and create interest in the subject by linking it to real issues within the subject-matter. The tutor should also encourage students to think independently and ensure that everyone respects each others opinions and suggestions. This relates to the mastery of interpersonal and communication skills and in particular, fluency in the use of collaborative online learning technologies (Dabbagh, 2007). Hence, tutors need to be exposed to this particular set of skills or "taught" how to equip themselves with these set of skills.

It was also suggested that tutors facilitate "deep" meaningful learning through collaborative discussions. This may be done by creating opportunities to build or construct knowledge together as a group. Another recommendation is to have tutors ensure that learning online is fun. The use of informal or conversational language pitched at the student's level with use of smileys and other emoticons would be desirable. For quantitative subjects it was strongly 
suggested that an equation editor be made part of the myLMS online forum tool. Without this, level of interactions would be low.

It was also recommended that for effective implementation of future online learning via discussion forums, that OUM makes it clear to the tutors that their role as an online tutor is equally, if not more important than their role as a face-to-face tutor. OUM needs to review the payments for tutors who need to effectively lead and moderate the online discussions. Guidelines and expectations must be made clear during the tutor training conducted by the university. Rubrics for evaluating learners' participation need to be reviewed, with a strong possibility of removing marks awarded for frequency of postings. For quantitative subjects, the group recommended that equation editors be made available so that postings may include use of mathematical expressions. Finally, it was also recommended that apart from giving the Best Online Tutor award, OUM recognizes all its good online tutors for their effectiveness by awarding them certificates of recognition.

\section{CONCLUSION}

The study aimed to improve online learning through discussion forums at OUM. Having gone through seven years of implementation with adjustment along the way, the study was timely in determining how effective the implementation is. This was judged from the way tutors and students interacted online based on the $\mathrm{COI}$ model as it is believed to be a practical approach to ensure construction of "deep" and meaningful learning. It is also believed to be a model that will help empower learners and tutors to create a valuable learning community that will further enhance learning opportunities and help students to achieve a better understanding of the subject matter with the guidance of their tutors.

In order to better support future implementation of online discussions at OUM, several recommendations were made through the study. These would be communicated to the tutors through the Tutor Handbook and "taught" during the next tutor training sessions before the September 2008 semester to about 3,500 new and senior tutors. A new grading matrix is also being proposed for the award of marks to students for immediate implementation.

\section{REFERENCES}

Abas, Z.W. \& Kaur, A. (2004). Preparing tutors for online collaborative learning at the Open University Malaysia. Proceeding of ICCE 2004, Melbourne, Australia, December.

Dabbagh, N. (2007). The online learner: Characteristics and pedagogical implications. Contemporary Issues in Technology and Teacher Education, 7(3), 217-226.

Garisson, D.R. (2006). Online collaboration principles. J. Asynchronous Learning Networks, 10(1), 25-34. Retrieved 27 July 2008 from http:/www.sloanc.org/publication/jaln/v10n1/

Garrison. D.R., Anderson, T. \& Archer. W. (2000). Critical Inquiry in a text-based environment: Computer conferencing in higher education. The Internet and Higher Education. 2 (23), 8-105.

Garrison, D.R., Arbaugh. B., Cleveland-Inner, M., Diaz. S., Ice, P., Richard, J., Shea, P. \& Swan, K. (2008). Community of inquiry framework: Instrument development, validation 
and application. International Conference of the new Canadian Network for Innovation in Education (CNII). Banff, April.

Garrison. D.R. \& Archer, W. (2000). A transactional perspective on teaching and learning: Framework for adult and higher education. Oxford, UK: Pergamon.

Hannafin, M., Land, S., \& Oliver, K. (1999). Open Learning environments: Foundations, method and models. In C. M. Reigeluth (Ed.), Instructional design theories and models (Vol. II). Mahwah, NJ: Erlhaum.

Ice. P., Arbaugh. B., Diaz, S., Garrison, D.R., Richardson, J. Shea, P., \& Swan, K. (2007). Community of inquiry framework: Validation and instrument development. The 13th Annual Sloan-C International Conference on Online Learning, Orlando, November. Retrieved 28 May. 2008 from

http: //communitiesofinquirv.com/files/Sloan\%20Col\% 200rlando\% 2007.pdf

Kuldip. K. \& Abas. Z. W. (2004). Implementation of a collaborative online learning project at Open University Malaysia. Proceeding of the Southeast Asia Association for Institutional Research (SEAAIR) 2004 Conference. 21-23 September 2004, Wenzhou, China, pp. 453-462,

$\mathrm{Li}, \mathrm{Q}$. (2004). Knowledge building community: Keys for using online forums. TechTrends, 48 (4), pp. 24-28, 70.

Luppicini, R. (2007). Online learning communities. Charlotte, NC: Information Age Publishing. Muilenburg, L. \& Berge. Z. (2000). A framework for designing questions for creating learning. DEOSNEWS.10(2).

Wang. M. \& Kang, M. (2006). Cybergogy for engaged teaming: A framework for creating learner engagement through information and communication technology. In D. Hung and VI. S. Khine (eds.). Engaged learning with emerging technologies. 225-253. Dordrecht, The Netherland, Springer. 